\title{
The New Refugee System: Success or Failure?
}

\author{
by Howard Adelman
}

It is too early to provide any definitive judgement on the success of the new legislation concerning refugee claimants made within Canada or at our border. After all, the legislation has only been in effect for five months. But it is not too early to take a preliminary reading.

Two criteria for judging the system are fairness to genuine refugees and efficiency and cost effectiveness in processing claims. As a by-product of such efficiency, bogus claims will be dramatically discouraged, further, enhancing the efficiency of the system.

\section{History}

The refugee support groups, which virtually unanimously opposed the new legislation, did agree that an efficient new system was needed which would provide a rapid turnaround time, thereby discouraging bogus claimants. But they bitterly fought the new legislation. There were three major grounds for their opposition. They were opposed to the Safe Third Country provision on which to judge whether an individual was eligible to make a claim; they advocated universal hearings and opposed the use of preliminary hearings to presort claims; finally, they wanted a review system to catch errors and to ensure similar standards for assessing claims were used across the country.

The notion of a Safe Third Country provided that if a claimant arrived via a third country where the claimant could have made a refugee claim, the claimant would not have been eligible to make a claim in
Canada. In the eventual legislation, the requirement provided that the claimant had to sojourn in that safe country for at least two days. Further, the Minister had assured the public that the Safe Third Country provision would not apply to specific groups of refugees where the countries in which the claimants had sojourned had a poor record of accepting claims.

The legislation also provided for preliminary hearings to assess whether claimants were credible or eligible to even have a hearing. The legislation made no provision for a review system within the Refugee Board.

As a result of the conflict over the legislation, the new legislation and its implementation was delayed at least two years. In the meanwhile, the number of cases coming to Canada more than doubled each year from a base of approximately 8,000 in 1986. The backlog grew to 115,000 cases with an open door to abuse the system.

Has the government been proven correct in fighting so hard and long for the new legislation?

\section{Safe Country}

Before the system was introduced, the government shelved the Safe Country provision as unworkable. The major centre piece of the new legislation was abandoned before the system was even started.

\section{Preliminary Hearings}

The second major point of contention was the absence of full refugee hearings for every claimant before an independent Refugee Board. Instead, Preliminary Hearings were introduced to weed out non-credible and ineligible claimants. How has the Preliminary Hearing System worked?

From January to May 1st, of 2,806 claimants, 2,504 were given preliminary hearings. Of these, 114 (5 per cent) were withdrawn or abandoned and, of the remaining $2,390,2,210$ (93 per cent) were referred to a full hearing. Of those rejected, 2 were not found to be eligible and 178 were found not to have a credible claim. That is, the preliminary hearings end up eliminating only 7 per cent of the claimants since one can presume the other 5 per cent of withdrawn or abandoned cases would have followed the same pattern whether they went to a preliminary hearing or to a full hearing. There is even a possibility more might be abandoned if they went directly to a full hearing.

To eliminate 7 per cent of claimants processed (180 of 2,390$)$ in a preliminary hearing, an expensive and cumbersome extra step in the refugee procedure was introduced. The extra cost of the Preliminary Hearing Stage is estimated to be at least $\$ 16$ million for the government and $\$ 3,750,000$ for the refugees or legal aid.

The estimate is arrived at by several calculations. For example, if the cost of the refugee claims process is $\$ \mathbf{1 0 0}$ million per year, if central office costs (library, communications, administration, etc.) are estimated at 20 per cent, and if the preliminary hearings are even estimated to cost one fifth of the balance (half the time for half the number of cases), then the cost is about $\$ 16$ million. Similarly, 
the cost can be calculated by estimating the time of an average hearing that is challenged and the overhead cost of interpreters, refugee board members, immigration officials or refugee hearing officers, etc. The estimated cost of the claims that go to a full preliminary hearing where there is a government challenge. is estimated at about $\$ 3,000$ per hearing for an estimated 4,000 hearings, or a cost to the government of about $\$ 12$ million (excluding the legal costs of counsel to the refugee claimant) if the claims are restricted to one half a day per hearing. (In fact, some of the preliminary hearings are taking a full day and, in effect, have become refugee hearings, which, unfortunately, merely have to be repeated at the full refugee hearings which follow.) Further, if the other 4,000 preliminary hearings in which no challenge takes place is also calculated at one-third of the cost of a full hearing, then this adds another $\$ 4$ million to the bill for a total of $\$ 16$ million.

In other words, if only the estimated direct costs to the government of the preliminary hearings are taken into account (and not the indirect costs or the costs of postponed preliminary hearings or the costs incurred directly or indirectly by the refugee claimants), the cost to eliminate one refugee claimant from the system at the preliminary stage is about $\$ 28,500$ even if the hearings are completed in half a day. That is, if there are an estimated 8,000 hearings, and 7 per cent of these are eliminated (about 560 ), and the direct costs of eliminating those claimants in 1989 is $\$ 16$ million, then the direct cost per claim eliminated is $\$ 28,500$.

In addition, the Preliminary Hearing stage builds in the potential for a new backlog as about two-thirds of those challenged failed to get their hearing within the first month let alone within 48 hours of arrival as initially expected by the department. Refugee Board members have to hear the claims of almost half of those

making claims twice, a terrible waste of very expensive personnel who could be spending their time giving refugees a full hearing, thereby speeding up the process. Further, of those who went to a preliminary hearing, postponements were presumably allowed to enable the refugees to arrange for counsel and/ or allow counsel to prepare their case, a time interval that would have been

\section{The Preliminary} Hearing may go the way of the Safe Country Provision, and follow numerous Royal Enquiry Reports and obsolete or unworkable legislation onto the dusty shelves of history.

sufficient to prepare for a full hearing. In other words, to eliminate only 7 per cent of claimants at a cost of $\$ 16$ million or $\$ 28,500$ per claim without any significant saving in the processing time and with a potential to build a new backlog, an extra step was introduced which significantly slows down a system which depends on a fast turnaround time to discourage bogus claimants.

The Preliminary System is costly. It has a low rate of effectiveness. Further, it may also be unfair. Of the claims rejected in the first month where we examined each of the claims rejected at the preliminary hearing stage, at least 2 and possibly 3 should not have been. An Ethiopian claimant was rejected; he not only had a prima facie credible case, but seems to have a provable case as a Convention refugee. A claimant from China slit her wrists upon being rejected at the preliminary hearing; in subsequent news reports we read about some grisly details of her case, including the torture and death of a family member at the hands of government authorities. She may not have a provable case as a Convention refugee, but she appeared clearly to have at least a case that deserved a full hearing. Subsequently, on compassionate grounds, the Minister of Immigration allowed her to stay. Whether the refusal of the psychiatrist to release her to face a deportation hearing was a factor in this decision, we are unable to say. This means that on fairness grounds alone, if the first month provides any indication, there seems to have been an error rate of at least 10 per cent that we know of in the preliminary hearing stage, a very high rate of error when one understands that this process is about life and death issues.

There are already hints that the government is considering shelving the Preliminary Hearings by gradually reducing the number of challenges and letting more and more of the claims go directly to a full hearing. The Preliminary Hearing may go the way of the Safe Country Provision, and follow numerous Royal Enquiry Reports and obsolete or unworkable legislation onto the dusty shelves of history. This would be a commendable de facto solution to an element of the legislation that is very costly, of little effect and which builds a potential for a new backlog quite aside from the considerations of unfairness. The Preliminary Hearing process could be kept as a reserve to handle cases of claimants from nonrefugee producing countries, particularly if even small numbers begin to appear on Canada's doorstep. 


\section{A Review System}

Then there will be only one major area of dispute with the refugee support groups across the country the need for a review system. The elimination of the Safe Country provision would have been unworkable and a political embarrassment; it was eliminated because of its own inherent flaws and proved unnecessary in any case. The elimination of the Preliminary Hearing as a general procedure will result from its high cost and ineffectiveness, though the political embarrassment of some of the unjust decisions may also help bring about its reservation for very restrictive application.

But a review system will not save money; it will cost money even if far less than the cost of the Preliminary Hearings. This change will be much harder to achieve. One cannot expect the government to capitulate on a point of pure fairness which costs money when it has so stubbornly clung to two flaws in the legislation, losing a very important two years, when those flaws were not only unfair, but costly, unworkable and inefficacious.

The one possibility for introducing a review is the political not the financial cost. These costs arise from two different sources. The most critical is the fate of the returnees rejected through the system. So far, three cases of returnees rejected by the refugee claims system have beenreported as possibly having suffered upon their return, though there is no direct evidence as yet. The second cost arises within the system itself if some political appointees to the Refugee Board prove to be weak and a potential source of embarrassment as a result of their pattern of decision making. Neither situation would be welcomed by the government or the Refugee Board. Whatever the critics may say of the government, it would be wrong to accuse the government of deliberately wanting any individuals to be

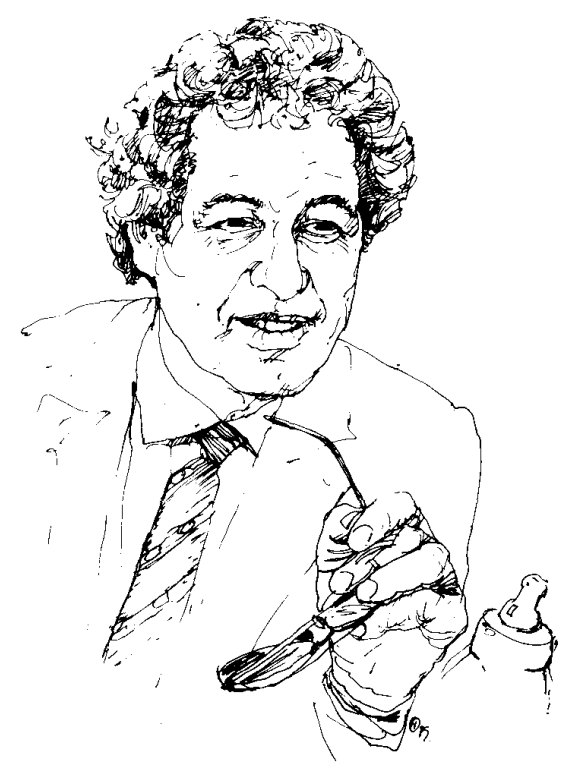

Howard Adelman

returned to their countries of origin if they end up being persecuted. For purposes of self protection, the Refugee Board may introduce its own internal review procedure. Though such a weak form of administrative review would not meet the claim for a full right of appeal on substantive grounds, it is likely to be the best that can be expected at this time. And if virtually no genuine refugees can be proven to have been refouled once such a system were in place, then this is as far as the improvements are likely to go in the foreseeable future. The pity is, these were precisely the elements in the compromise worked out by Jim Hawkes when he was the Tory Chairman of the House Standing Committee on Labour, Employment and Immigration in the previous Parliament.

\section{The Explanation}

If these changes are to come about, it is important to understand the reasons for these errors in the legislation. If the errors arose from an ideological bias by the Tory government against genuine refugees, then the changes are less likely to occur. If, however, they arose for other reasons, then alterations are more likely. That likelihood will be enhanced if the real source of the problem is identified and the correct strategy is adopted.

A combination of three factors which had led the government to introduce the new legislation and alienate the entire non-government refugee support system has been suggested. First, a small core of Tory backbenchers, and the portion of the public supporting them, were antithetical to any refugees claiming refugee status within our borders. Their motives varied from an ethics of Me first, a desire to save money and to racist beliefs; their ideology was best expressed in the Nielsen report on immigration. Secondly, civil servants wanted to control the selection of those who came into Canada; they were not anti-refugee but were critical of a situation in which a large number of spontaneous arrivals threatened their ability to plan and control the numbers and types of individuals allowed to enter Canada. Thirdly, pragmatic politicians, who were also not anti-refugee, were responding to the backlash against the spontaneous arrivals as evidenced by the flood of critical mail received when less than 200 Tamils arrived off the coast of Newfoundland.

Just before Christmas, government immigration officers were sent a Christmas present. They were instructions ("the most important set they would read") describing the Program Delivery Strategy for implementing Bill C-55 and Bill C-84. Those instructions seem to confirm speculations about the intent of government civil servants who promoted and defended the new legislation.

The Program Delivery Strategy in implementing Bills C-55 and C-84 provides direct evidence to support 
the preeminence of the second motive and suggests it will be the most influential factor in the administration of the new laws. These most important instructions stress, in its own words, "control issues". "The Perfect Plan", as the Strategy asserts, "is not a plan at all. Rather it is an accounting exercise." The object of the exercise is to control the intake of numbers. What about protecting genuine refugees?

The instructions assert that there are "two extremely important ideas contained in the strategy". The first asserts that the Commission wants "genuine refugee claimants to go to the new Immigration and Refugee Board". Note the innovative use of language. Previously, the Canadian public had been bombarded with a false dichotomy: genuine refugees were those whose claims were granted and all others who claimed refugee status were bogus. This was in spite of the fact that the government statistics suggested that there were three categories of refugee claimants, not two: successful refugee claimants ( 30 per cent) and unsuccessful claimants, the latter in turn dividing into bogus claimants (19 per cent) - those making fraudulent claims - and those coming from refugee producing situations in which they felt their lives were in danger but were unable to prove that danger represented a well founded fear that they, as individuals, were targeted for persecution.

The Program Delivery Strategy applies this linguistic distortion to the preliminary hearing stage. The preliminary hearing is not (according to the instructions) designed to to sort out credible and eligible cases from non-credible and ineligible ones, preventing the clearly bogus claimants from obtaining a full hearing and ensuring that anyone with a credible case at all goes before the Refugee Board. The instructions do not assert that, "We want all credible claims to go before the Refugee Board." They assert, "We want genuine refugee claimants to go to the new Immigration and Refugee Board".

One can give these instructions a second reading. One could argue that they mean that the immigration staff are to be as helpful as possible in ensuring that all genuine refugee claimants go before the new Refugee Board, but others may be allowed to go as well. It is a possible reading. But the following factors suggests that it is not the intended meaning. First, no where in the instructions are officers told that their responsibility is not to determine who is a genuine refugee or not, but only to determine who has an eligible or credible case. Secondly, if officers are instructed to ensure that genuine refugees go before the Refugee Board, this implies that they have a responsibility for determining who is a genuine refugee and not simply determining who has a credible and eligible case. Thirdly, we can now understand why the lawyer defending the refugee claimant from mainland China, who slit her wrists when she was denied a hearing at the preliminary stage - in spite of the fact that she claimed her father had been murdered by the Communist regime - was shocked at the outcome. As he stated in an interview on the $C B C$, he thought he had only to produce enough evidence to prove the claimant had a credible claim; he did not think he had to prove at the preliminary hearing she was a genuine refugee and he blamed this erroneous assumption for the outcome of the preliminary hearing. The rejection of the Ethiopian refugee claimant who had a clear prima facie case as a refugee but had an inexperienced designated counsel to defend him at the preliminary hearing is another instance indicating that the two stage process is not one to sort out credible from non-credible claimants at the first stage, but to decide who is a genuine refugee. The assumption is that, as much as possible, all refugee claimants who go before the Board should be able to prove they are genuine refugees. Since, 93 per cent of the refugee claimants who had a full hearing received a favourable decision, the statistics support such a contention. This suggests that the preliminary hearings are, in fact, serving to select refugees and not just eliminate bogus claimants.

But there is a fourth piece of evidence which is even clearer in suggesting that the immigration officers were being instructed to determine who is a genuine refugee and not just who is a credible and eligible claimant. The instructions project the statistics which will result from their strategy. Bissett predicts that after one year there will be a 60 per cent decline in claims and that "there will be an out-take of 10 per cent at the front end of humanitarian and compassionate cases." This means that only 30 per cent of the historical number of claims will appear before the Refugee Board for a full hearing. This is precisely the percentage of traditional claimants who were able to prove that they were refugees. In other words, the intake into the Refugee claims system will be reduced by 70 per cent, the exact percentage of claimants who were unable to prove they were refugees. Not only would all bogus claimants be eliminated from the system. All other cases who have difficulties proving their claims, whether or not their claims are credible and whether or not they are eligible, will be eliminated from the system at the first stage.

The second extremely important idea stressed throughout the instructions reinforces the interpretation that the main thrust of the top civil servants in the Immigration Department is to have control. As the introduction to the instructions conclude, "The main thing to remember is that we are in charge of this program and we intend to manage it." The main purpose is not to ensure that anyone with a credible and eligible claim gets a full and fair hearing. The main thing is not to ensure that the Refugee Board is given the responsibility and the opportunity to decide who is and who 
is not a genuine refugee. The intent is "to reduce the intake into the refugee process to a level which the Board can handle on an ongoing basis." Management needs, not refugee needs, will determine the level at which the system will operate. We are in charge; we are in control; we manage. This is the ideology of the immigration civil service as articulated by Joe Bissett, the Executive Director.

But is this fair? The instructions, after all, state that the function of the new bills are to "combat abuse". "The thinking behind C-55 was that as claims were quickly decided negatively on grounds of eligibility, credible basis, and by the Refugee Board after a full hearing, the word would get around that there was no advantage to be gained by bogus people claiming refugee status." This seems a very commendable strategy. But the strategy as outlined in the document suggests another more important goal - control, reduction of numbers, even if those numbers happen to be refugees.

As the strategy document itself makes clear, Bill C-55 and Bill C-84 are just part of the control strategy. $\mathrm{T}$ he broader strategy includes the use of visas, fraudulent documentation detection, prevention of embarkation through fines on the airlines, etc. "Prevention of arrival is as important as as removal in reducing demand upon the refugee producing process." The document further notes that, "the target for the External Affairs 'outtake' from the system should be considerably higher than any target set for removals."

This means that the department could eliminate, on a statistical count, the exact percentage of cases who could not prove that they were refugees. But this has, in fact, been the impact of the new legislation without the use of the Safe Country provision. Further, it would be the impact without the use of Preliminary Hearings.

In other words, whether we like the strategy or not, whether we applaud or disapprove of its effects, the strategy has been successful. And it does not require either the Safe Country provision or the Preliminary Hearings to achieve that success. In other words, the civil servants can feel they have achieved their goals while allowing the Preliminary Hearings to whither away and without pressing to introduce the Safe Country provision, provided, of course, they are not absolutist in their goals.

\section{Principles}

One could, of course, insist the battle be joined on principles. Though the Safe Third Country provision has already been shelved as unworkable, the strategy document suggests that if it had been used as envisioned by the civil servants, then the United States would have been classified as a Safe Third Country, in spite of the fact that the USA had a terrible track record during the Reagan administration, according to its own courts and statistical records, for granting genuine Central American refugees refugee status in America. As the strategy document notes, "the returnto-safe-country provisions are expected to have a substantial impact on demand" along with the deterrent factor of directing people back to the United States. In fact the strategy document went even further; "We want cases which are removable on the basis of arrival from a Safe Third Country ... to be detained because removal will be imminent." Detention was to be used not to protect Canadians but to increase the efficiency of the controllers.

One could argue that the battle needs to be fought on principle to prevent the possible introduction of such measures as detention or the Safe Country provision. This may be valid, but it might be preferable to achieve what can be achieved where there is little disagreement on the basis of effectiveness, strategy and ideology.

We did not need the Safe Third Country provision to reduce the intake significantly. We do not need the system of Preliminary Hearings to reduce the intake. In other words, the civil servants who want to control the intake into the system can boast that they have already achieved their goal (setting aside whether such a goal is desirable or not).

There are already hints that the Preliminary Hearing System may follow the practice of a de facto shelving without any admission by the architects who constructed the system that they were wrong. Raphael Girard, labelled as the chief architect, admitted as much in a Southam News Interview by Joan Bryden reported in the Toronto Star on February 6th. As Girard is reported, "The government is also considering contesting fewer claims at the preliminary hearing so more go directly to a full hearing." They presently challenge less than 50 per cent, so if there is to be a significant decrease in challenges, the extra costs and delays as well as the risks of unfairness may lead to the reality that virtually all claims go to a direct hearing.

\section{Conclusion}

One might gloat over this victory. It appears that the government fight for the Safe Third Country provision and the preliminary hearings, which in themselves probably led to a two year delay in passing and implementing the new legislation and the consequent huge build-up in claims, was a total waste of time. But the point is not to gloat, but to implement de facto changes to improve the system. We trust these are in fact in process even if there is no public announcement to prevent any loss of face.

\footnotetext{
Howard Adelman is the Director of the Centre for Refugee Studies at York University and the Editor of Refuge.
} 